inquiry, which revealed the fact that a hospital case may spread both scarlet fever and diphtheria over a wide area, and in a severe form, without so much as touching the home, it strikes one as a little odd that medical officers of health have still the courage to declare that the hospitals with which they are associated are doing no harm as their "returns" are so few.

That the discovery will be made that occurrences comparable to the Ditcham outbreak are not infrequent is, in my opinion, certain. The judicial spirit in which this inquiry was conducted inspires the hope that the Local Government Board has determined to deal with the aggregation question on its merits. We desire no more. As Dr. Darra Mair pointed out, the trouble must be sought, not in the crowded centres, but in the investigation of outbreaks which occur in isolated districts where cases can, with a degree of certainty, be traced to their origin.

So convinced are sanitary authorities of the unwisdom of returning their discharged hospital patients directly to their homes that handbills are published which give warning of the danger of such a proceeding. Such patients, it is suggested, should be sent into the country districts for at least a fortnight. What this may mean may be gathered from a study of the Ditcham outbreak. In the next year's annual report we shall find the occurrence of epidemics in the outlying districts furnishing the explanation of the high attack rate in the city through the instrumentality of markets and fairs. It is more than can be expected of a plain man not to smile. The confession that discharged hospital cases remain a source of danger to their surroundings forms a curious commentary on the fact that it was to prevent this that they were removed to hospital. What other object was to be attained? Surely the welfare of the patient was not the desideratum when we remember that he must run the gauntlet of secondary infection, post-scarlatinal diphtheria, and a host of other aggregation ills.

Many explanations of "return cases" have been forthcoming. It does not afford comforting reflection that some of these are very ingenious. Premature discharge for a long time held sway and medical officers of health had to stand the brunt of actions for damages, until it was discovered that peeling was no certain sign of lingering infectivity (although people had been fined and imprisoned for exposing their children during the peeling stage). Then otorrhœa and rhinorrhcea took up the running. I have proved elsewhere that healthy people who have through errors of diagnosis been kept in hospital have, on their extrication, spread fever in a bad form. There is another facet of the aggregation question which might well form the subject of Government inquiry-namely, what part was played by aggregation in the late war? It was not all Modder river water. I have seen without surprise the suggestion of protracted infectivity in regard to enteric fever. Are we nearing the truth? These questions are of great importance to us as a nation and they are not to be got rid of with a wave of the hand.

I am, Sirs, yours faithfully,

Nottingham, Oct. 11th, 1902. EDWARD DEAN MARRIotT.

\section{THE ILL-EFFECTS OF SUGAR IN INCIPIENT CATARACT.}

\section{To the Editors of $\mathrm{TH} \mathrm{EANO \textrm {T }}$}

SIRS, - In many cases of incipient cataract occurring in adults it has been my practice during many years to advise abstinence from, or sparing use of, sugar in the diet, although most of these patients had urine entirely free from sugar. That $m y$ practice is unusual I gather from patients who have consulted others and have told me "that no sugar could be found in their urine" and that therefore my advice was unsound. Patients with incipient cataract are not always very cheerful about themselves and by no means should be deprived of any harmless pleasure. But is the use of sugar harmless in such cases? There is plenty of scientific evidence that cataract may be formed by sugar when taken in excess by animals and it seerns cuite probable that in many cases the consumption of sugar, though not injurious to the general health, may hasten the formation of cataracts. Of course, I am supposing that it is not desirable to hasten, but rather to retard, the maturity of these cataracts, and in these remarks I am not concerned with methods, mechanical or other, to hasten matters. Nor is it suggested that every patient should be restricted in the use of sugar but that some opinion should be formed in every case just as we examine the urine for sugar.

Take the case of a man, aged 69 years, who can read J. 2 readily with his glasses and ${ }_{1}$ easily unaided with each eye and has in each eye equally marked evidences of lens opacity. He read without glasses until the age of 55 years (low myopia). He has ailments of a gouty or rheumatic character with no sugar in the urine. It would be my practice to restrict such a patient in the use of sugar and sometimes I find that sugar has been taken in excess (sweets and chocolate). Saxin or saccharin makes a fair substitute for sugar and there can be little doubt that some of his aforesaid ailments were made worse by the careless use of sugar and thus the patient gains benefit by abstinence. Experiments on trout were made many years ago proving that cataracts in these fish were caused by sugaring the water in which they lived. Experiments more lately both in fishes and frogs give the same results. Cataracts have been induced in rabbits by the subconjunctival injection of sugar. Weir Mitchell caused cataract in frogs by the subcutaneous injection of sugar. These, with the experiments with naphthalin by Bouchard, are most interesting in connexion with diabetic cataracts.

There is thus much evidence ${ }^{1}$ that excess of sugar in the system will bring about cataracts and it seems probable that excess of sugar may occur without any evidence of ill-health or glycosuria. It would be an unduly strong measure to cut off all use of tobacco from our patients because we know that there is such a disorder as tobacco amaurosis, but if a patient who smokes has a commencing atrophy of the optic nerve or a blindness which cannot be otherwise accounted for, as this blindness may be due to tobacco then smoking for him should be stopped. In many patients with incipient cataract the use of sugar should be restricted, as it is impossible to feel sure that the sugar is harmless. In suitable cases it will be found that the general health is improved by abstinence from sugar, and among my notes of several thousand cases of disorder of the eye I find sufficient evidence to encourage me in the belief that the progress of cataract has been retarded by my advice.

I am, Sirs, yours faithfully

Cambricge, Oct. 11th, 1902. GEORGE WHERRY.

\section{EXPLOSIVE ERUCTATIONS.}

To the Editors of THE LANCET.

SIns,-It was during a trip to Australia in the year 1886 that I met with a case similar to the one described by Dr. A. A. Martin in ThE LAANCET of Oct. 11th, p. 991. The patient was an alcoholic and suffered from chronic gastritis. One day he came to me much alarmed, because on lighting a short piece of cigar, when eructating stomach gases, a slight explosion had taken place and singed his moustache. Shortly after seeing this case I read of another reported in 'THE LANCET by, I think, Sir William Gairdner. I am, Sirs, yours faithfully,

$$
\text { EDWARD HoRDER, F.R.C.S. Edin. }
$$

Limpsfield, Oct. 14th, 1902.

\section{SYPHILIS AND IIFE ASSURANCE. To the Editors of THE LANCET.}

SIRS,--In his Note on Syphilis in Relation to Life Assurance, with an Examination of 500 Consecutive Claims, in THE LANCET of Sept. 27th, p. 867, Dr. F. Parkes Weber refers to the statistical statements published by Professor J. W. Runeberg of Helsingfors, whose "figures" he declares to be open to "various objections." This they undoubtedly are, and it is therefore somewhat surprising to find that Dr. Weber "on the whole "accep's Professor Runeberg's conclusions." "He also gives ex] re:sion to the "belief that Professor Runeberg can hardly have much over-estimated the influence played by syphilis in the series of cases which he investigated." At the last International Congress of Medical Assurance Officers Dr. Salomonsen of Copenhagen exposed the many fall zoies of Professor Runeberg's method of marshalling his postmortem evidence. In a still more forcible manner the same thing bas been recently done by Dr. Gollmer of Gotha, who holds up Professor Runeberg's statisties as a kind of warning example, as " eine Syphilisstatistik, wie sie nicht sein

1 Bence Jones, Richardson, Graefe, Forsster, Jacobson, Bouchard, Hirschberg, Deutschmann, Fuchs, Berger, and others. 